\title{
Comparison of Lichtenstein, Laparoscopic Transabdominal Preperitoneal, and Laparoscopic Totally Extraperitoneal Groin Hernia Repair and our experience with 104 Patients
}

\section{İsmail Cem SORMAZ, Ömer Cenk CÜCÜK, Elnur HÜSEYNOV, Levent AVTAN \\ Department of General Surgery, İstanbul University İstanbul School of Medicine, İstanbul, Turkey}

\section{ABSTRACT}

Objective: The aim of this study was to compare the results of Lichtenstein repair (LR) and transabdominal preperitoneal (TAPP) and totally extraperitoneal (TEP) laparoscopic repair in groin hernias.

Methods: The medical records of 104 patients who underwent groin hernia repair between January 2011 and December 2015 were retrospectively analyzed. Patients who underwent LR were defined as group $1(\mathrm{n}=29)$; those who underwent TAPP laparoscopic repair were defined as group $2(n=42)$, and those who underwent TEP laparoscopic repair were defined as group $3(n=33)$. The patients in the groups were compared according to their demographic findings, body mass index, operative time, and post-operative complications.

Results: One patient in group 1, 10 patients in group 2, and seven patients in group 3 had bilateral groin hernias. Four patients in group 2 and two in group 3 had recurrent hernia and a history of previous LR. The mean operation time was $50.13 \pm 14.28$ min in group 1, $69.61 \pm 22.19 \mathrm{~min}$ in group 2 , and $63.87 \pm 18.09 \mathrm{~min}$ in group 3 . The mean hospital stay was 1.4 days in group $1,1.2$ days in group 2 , and 1.1 days in group 3 . No major complication was encountered in early post-operative period in all groups.

Discussion: Laparoscopic procedures are commonly used in hernia surgery, particularly in recurrent and bilateral cases. However, in primary and unilateral cases, LR and laparoscopic procedures have similar results. From the findings of this study, in laparoscopic hernia repair, the most important factor affecting the selection of the method is the experience of the surgeon.

Keywords: Groin hernia, Lichtenstein, TAPP, TEP

\section{Introduction}

Although inguinal hernia repair is among the most frequently performed elective operations in general surgery clinics, there is still no technique that could be described as the ideal technique. After Bassini described the inguinal hernia repair in 1887, several methods have been developed before the implementation of laparoscopic hernia repair (1). After Lichtenstein started using the patch repair method, a decrease in the recurrence rates made it the most commonly employed method (2). Transabdominal preperitoneal (TAPP) and total extraperitoneal (TEP) approaches were described after laparoscopy gained its current use $(3,4)$. Minimally invasive methods come to the forefront because of they are less painful, require less analgesics, provide better cosmetic results, lead to an early return to work, and cause fewer wound problems during the early postoperative period $(5,6)$. However, negative aspects such as higher costs and a longer learning curve should not be disregarded (7).

In this study, we aimed to evaluate the outcomes of patients in whom the Lichtenstein repair (LR), TAPP, and TEP were performed for inguinal hernia.

Cite this article as: Sormaz IC, Cücük ÖC, Hüseynov E, Avtan L. Comparison of Lichtenstein, Laparoscopic Transabdominal Preperitoneal, and Laparoscopic Totally Extraperitoneal Groin Hernia Repair and our experience with 104 Patients. Bezmialem Science 2017; 5: 107-11.

Address for Correspondence: İsmail Cem SORMAZ; İstanbul Üniversitesi, İstanbul Tıp Fakültesi, Genel Cerrahi, Anabilim Received : :11.07.2016 


\section{Table 1. Demographic data of patients}

\begin{tabular}{|c|c|c|c|c|}
\hline & Group 1 & Group 2 & Group 3 & All Groups \\
\hline Age & $55.62 \pm 16.99$ & $53 \pm 13.15$ & $52.45 \pm 4.96$ & $53.55 \pm 14.78$ \\
\hline Female/Male & $5 / 24$ & $1 / 41$ & $1 / 32$ & $7 / 97$ \\
\hline BMI & $25.7 \pm 3.1$ & $24.86 \pm 2.9$ & $25.23 \pm 3.0$ & $25.1 \pm 3.0$ \\
\hline Bilateral & 1 & 10 & 7 & 18 \\
\hline Right & 14 & 15 & 12 & 41 \\
\hline Left & 14 & 17 & 14 & 45 \\
\hline Recurrence & 0 & 4 & 2 & 6 \\
\hline Direct & 10 & 16 & 14 & 40 \\
\hline Indirect & 20 & 36 & 26 & 82 \\
\hline Others (obturator, femoral) & 0 & 0 & 0 & 0 \\
\hline Number of patients & 29 & 42 & 33 & 104 \\
\hline Number of sides operated & 30 & 52 & 40 & 122 \\
\hline
\end{tabular}

\section{Methods}

We retrospectively reviewed the files of 104 patients who underwent surgery for inguinal hernia and were followed up between January 2011 and December 2015. All patients were operated by two surgeons (LA and ICS) under elective conditions, and the selected surgical procedure did not affect the choice of surgeon. Three surgery techniques were performed by both surgeons. LR was applied to patients who desired spinal anesthesia and/or those who did not accept laparoscopic surgery. The surgery that would be performed in patients who preferred laparoscopic surgery was chosen by the surgeon considering the patient's condition. Strangulated or incarcerated cases were not included in the study. All patients were informed about the surgical technique and anesthesia in detail before the surgery. Of the patients who were included, 29 who underwent LR were defined as Group 1, 42 who underwent TAPP were defined as Group 2, and 33 who underwent TEP were defined as Group 3. The prophylaxis in all patients was $1 \mathrm{~g}$ ampicillin/sulbactam before the surgery. Postoperative analgesia was provided with intravenous paracetamol, and oral paracetamol treatment was applied for a week. Demographic characteristics, body mass index (BMI), the duration of surgery, and postoperative complications were compared among the groups.

Statistical analysis was performed using Microsoft Excel 2013 Professional Plus; ANOVA was used for three-group comparisons, and t-test was used for two-group comparisons.

\section{Results}

The mean age of the entire patient group was $53.55 \pm 14.78$ (range, 20-85) years. The mean age of patients in Group 1 was 55.62 \pm 16.99 (range, 21-85) years, that of patients in Group 2 was $53 \pm 13.15$ (range, 21-77) years, and that of pa- tients in Group 3 was $52.45 \pm 14.96$ (range, 20-81) years. No statistically significant difference was observed (ANOVA $\mathrm{f}<\mathrm{f}$ criterion, $\mathrm{p}=0.71$ ). Only seven of 400 patients were female (five in Group 1 and one each in groups 2 and 3) There was no significant difference among the three groups in terms of BMI $(25.7 \pm 3.1,24.86 \pm 2.9,25.23 \pm 3.0$, respectively) (ANOVA $\mathrm{f}<\mathrm{f}, \mathrm{p}=0.98)$. Bilateral, right, and left inguinal hernia were observed in 1, 14, and 14 patients, respectively, in Group 1 $(\mathrm{n}=30)$; in 10,15 , and 17 patients, respectively, in Group 2 $(\mathrm{n}=52)$; and in 7, 12, and 14 patients, respectively, in Group $3(n=40)$. In Group 1, no patients were operated because of recurrence. Four (two each with right and left inguinal hernia) patients in Group 2 and two (one each with right and left inguinal hernia) in Group 3 were operated for recurrent inguinal hernia (Table 1).

The mean duration of surgery was $50.13 \pm 14.28 \mathrm{~min}$ in Group $1,69.61 \pm 22.19 \mathrm{~min}$ in Group 2, and $63.87 \pm 18.09 \mathrm{~min}$ in Group 3 (ANOVA test result $f>f$ criterion, $p=0.000159$; when the groups were separately evaluated using t-test, it was found that Group 1 had a significantly shorter duration of surgery than Groups 2 and 3, and there was no significant difference in the duration between groups 2 and 3). When patients in whom bilateral intervention was performed to obtain a more homogeneous group were excluded, the mean duration of surgery was $49.25 \pm 14.29 \mathrm{~min}$ in Group 1, 62.85 \pm 22.2 $\mathrm{min}$ in Group 2, and 59.75 $\pm 19.47 \mathrm{~min}$ in Group 3 (ANOVA test result $f>f$ criterion, $p=0.000269$; when the groups were separately evaluated using t-test, it was found that Group 1 had a significantly shorter duration of surgery than groups 2 and 3 , and there was no significant difference in the duration between groups 2 and 3). The average postoperative hospital stay was 1.4 (range, 1-4) d in Group 1, 1.2 (range, 1-4) d in Group 2, and 1.1 (range, 1-3) d in Group 3 (Table 2). 


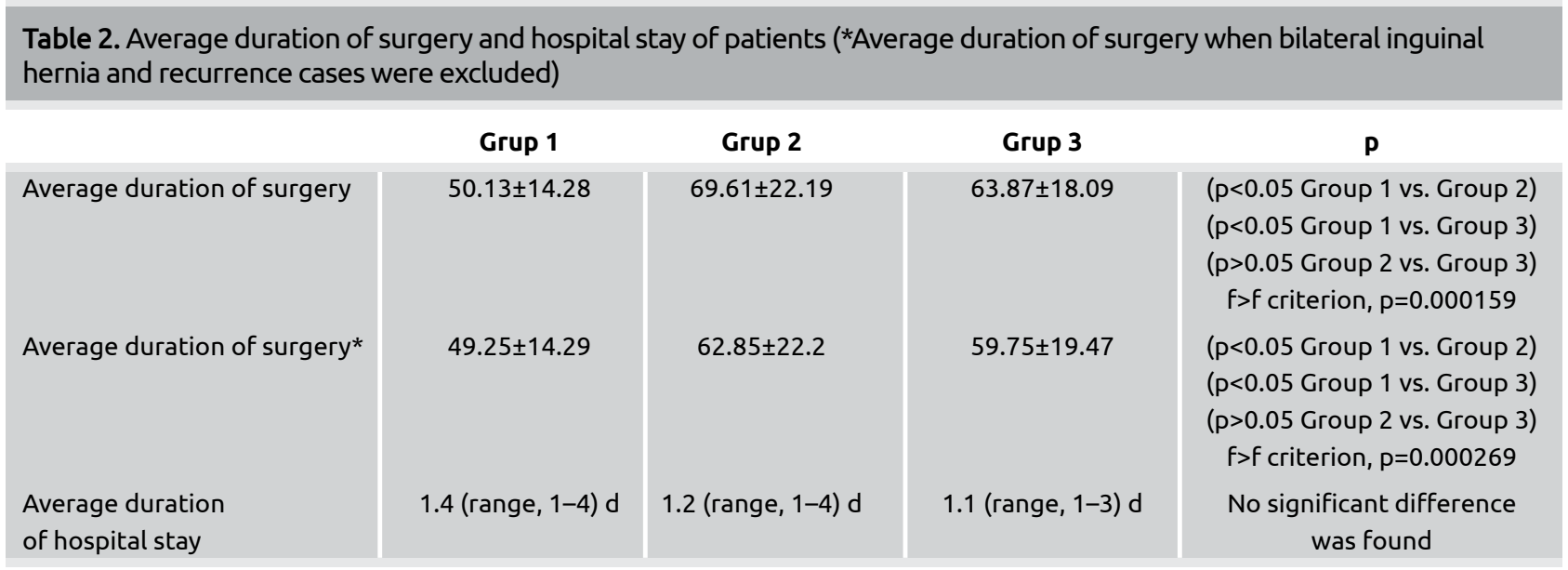

Table 3. Postoperative complications ( $n^{*}=$ number of sides)

\begin{tabular}{|l|c|c|c|}
\hline & $\begin{array}{c}\text { Group 1 } \\
\left(\mathbf{n}^{*}=\mathbf{3 0 )}\right.\end{array}$ & $\begin{array}{c}\text { Group 2 } \\
\left(\mathbf{n}^{*}=52\right)\end{array}$ & $\begin{array}{c}\text { Group 3 } \\
\left(\mathbf{n}^{*}=\mathbf{4 0 )}\right.\end{array}$ \\
\hline Scrotal edema & $1(3.3 \%)$ & $2(3.8 \%)$ & $2(5 \%)$ \\
\hline Wound infection & $1(3.3 \%)$ & $0(0 \%)$ & $0(0 \%)$ \\
\hline Hematoma & $1(3.3 \%)$ & $0(0 \%)$ & $0(0 \%)$ \\
\hline Chronic pain & $0(0 \%)$ & $2(3.8 \%)$ & $0(0 \%)$ \\
\hline Epididymitis & $0(0 \%)$ & $1(1.9 \%)$ & $0(0 \%)$ \\
\hline Early recurrence & $0(0 \%)$ & $1(1.9 \%)$ & $1(2.5 \%)$ \\
\hline Switching to open surgery & - & $0(0 \%)$ & $0(0 \%)$ \\
\hline
\end{tabular}

During the early postoperative period, scrotal edema developed in one patient in Group 1, and hematoma and wound infection developed at the site of incision in a patient using aspirin. In Group 2, scrotal edema was observed in two patients, inguinal pain lasting for 3 months in two, epididymitis in one, and early recurrence in one. In Group 3 , scrotal edema developed in two patients, and unilateral, early recurrence developed in one patient who underwent bilateral hernia repair. None of the patients who underwent laparoscopic surgery had port-site hernia, infection, hydrocele, testicular ischemia, and scrotal hematoma. All surgeries, which were laparoscopically started, were completed with the starting procedure without switching to open surgery (Table 3 ).

\section{Discussion}

Tension-free repairs using patches are currently more preferable than are primary tissue repairs in inguinal hernia surgery. It will not be possible to define a "gold standard method" without defining a method that completely eliminates recurrence. Although this rate has decreased to $0.12 \%$ with the introduction of LR (8), there is still no method that can be applied without recurrence. Laparoscopic interventions in hernia surgery gained importance after Arregui described TAPP (3) and Dulucq described TEP (4) in 1992. The frequency of the use of these methods has been increasing, and satisfactory results have been obtained with recurrence rates of $<1 \%$ after adequate personal experience (9). Although studies comparing TAPP and TEP in laparoscopic methods that are superior in terms of patient comfort have been conducted, the superiority of either of these methods has not been precisely determined. We retrospectively reviewed the files of 104 patients who underwent surgery for inguinal hernia and were followed up in our clinic between January 2011 and December 2015 and compared the results of patients in whom LR, TAPP, and TEP were performed.

Dedemadi et al have reported the duration of surgery of $45 \pm 8$ $\mathrm{min}$ in LR, $55 \pm 12 \mathrm{~min}$ in TAPP, and $56 \pm 9 \mathrm{~min}$ in TEP (10). Köckerling reported that the duration was significantly longer in TAPP than in TEP (11). The most important reason why peritoneal covering takes longer in TAPP than in TEP is the duration of opening and closing of peritoneum before the dissection. A comparison between the Tucker and continuous suturing techniques revealed that the Tucker technique shortened the duration of surgery by approximately $8 \mathrm{~min}$ (12). In our series, the duration of surgery was significantly shorter in LR than in laparoscopic methods. Although no significant difference was detected among the laparoscopic methods, the cause of the longer duration in TAPP may be the time spent during opening and closing the peritoneum.

Although the rate of intra-abdominal organ injury during laparoscopic hernia repair has been reported to be higher in patients in whom TAPP is performed, it varies between $0 \%$ and $0.06 \%$ in both techniques $(13,14)$, and the most frequently injured organ $(56 \%)$ has been reported to be the small bowel (15). In our series, no organ injuries were observed in any group.

In the literature; after LR, TAPP and TEP, the rates of scrotal edema have been reported as $7.14 \%, 13.1 \%$, and $15.48 \%$, respectively (16). In our series, these rates were 3.5\%, 1.9\%, and $5 \%$, respectively.

In a comprehensive analysis of patients undergoing LR and laparoscopic hernia repair using patch, although recurrence 
rates were lower in LR (recurrence in LR, $1.7 \%$ vs. recurrence in laparoscopic repair, $2.2 \%$ ), there was no statistically significant difference (17). In our series, no recurrence was detected in patients who underwent LR, but one recurrence was detected in each of the other two groups undergoing laparoscopic surgery. No recurrence or other complications were observed in the controls of LR patients at the 16th and 24th month of follow-up.

The occurrence of pain has been reported to be associated with patch use, and pain is less frequently encountered in patients in whom patches are not used. It has also been reported that, after laparoscopic surgeries, pain is less in patients in whom patches are used (18). In our series, only two patients in the TAPP group complained of pain lasting for up to 3 months after the 1 st week. The pain spontaneously reduced after both patients received regular analgesic treatment for 3 months. The pain advantage is directly related to the laparoscopic method, the structure of patch, the method of fixing the patch, and the surgeon's knowledge of anatomy. Therefore, the neural and vascular anatomy, particularly of the preperitoneal area, should be well known in laparoscopic inguinal repair (19). Patch selection is another important issue. We have preferably used lightweight patches that have a polypropylene structure and large pores.

Infection due to patch use is one of the most feared complications in hernia repair. Antibiotic prophylaxis has been reported to reduce the rate of infection from $1.2 \%$ to $0.2 \%$ in patients in whom LR was performed (20). This rate was reported to be $0.06 \%$ in laparoscopic hernia repair (21). In our series, before the development of infection following the drainage, intravenous antibiotic treatment was initiated in a patient in whom hematoma developed after LR. Apart from this patient, no infections developed in any other patient.

In addition to the fact that our study is retrospective, the small sample size is also a limiting factor. Furthermore, the number of patients who were regularly followed up was insufficient to assess long-term outcomes. We believe that more accurate results can be achieved through prospective randomized studies with broader case series.

\section{Conclusion}

Currently, when minimally invasive methods are an important part of surgical practice, there is no significant difference between TAPP and TEP techniques in laparoscopic hernia repair. Laparoscopic methods, which are known to be superior in terms of patient comfort, have recurrence rates that are similar to those of LR. The reason for the longer duration of surgery in TAPP than TEP, although not significant, can be explained by the fact that it requires a longer duration to open the peritoneum at the beginning of the surgery and close it at the end of the surgery. The method should be selected according to the laparoscopic experience of the surgeon.
Ethiscs Committee Approval: Authors declared that the research was conducted according to the principles of the World Medical Association Declaration of Helsinki "Ethical Principles for Medical Research Involving Human Subjects”, (amended in October 2013).

Informed Consent: Informed consent was obtained from each participant.

Peer-review: Externally peer-reviewed.

Author Contributions: Concept - İ.C.S., Ö.C.C., E.H.; Design İ.C.S., Ö.C.C., E.H.; Writing - İ.C.S., Ö.C.C., E.H.; Critical Review - L.A., İ.C.S.

Conflict of Interest: No conflict of interest was declared by the authors.

Financial Disclosure: The authors declared that this study has received no financial support.

\section{References}

1. Bassini E. Nuovo metodo sulla cura radicale dell'ernia inguinale. Arch Soc Ital Chir 1887; 4: 380.

2. Lichtenstein IL. Herniorrhaphy: A personal experience with 6,321 cases. Am J Surg 1987; 153: 553-559. [CrossRef]

3. Arregui ME, Davis CJ, Yucel O, Nagan RF. Laparoscopic mesh repair of inguinal hernia using a preperitoneal approach: a preliminary report. Surg Laparosc Endosc 1992; 2: 53-58.

4. Dulucq JL. Treatment of inguinal hernias by inserting a subperitoneal prosthetic patch using pre-peritoneoscopy (with a video film) Chirurgie: Memoires de l'Academie de Chirurgie 1992; 118: 83-85.

5. The MRC Laparoscopic Groin Hernia Trial Group. Laparoscopic versus open repair of groin hernia: a randomized comparison. Lancet 1999; 354: 185-190. [CrossRef]

6. Neumayer L, Giobbie-Hurder A, Jonasson O. Open mesh versus laparoscopic mesh repair of inguinal hernia. N Engl J Med 2004; 350: 1819-1827. [CrossRef]

7. Camps J, Nguyen N, Annabali R, Fitzgibbons RJ Jr. Laparoscopic inguinal herniorrhaphy: transabdominal techniques. Int Surg 1995; 80: 18-25.

8. Amid PK, Shulman AG, Lichtenstein IL. The Lichtenstein open "tension-free" mesh repair of inguinal hernias. Surg Today 1995; 25: 619-625. [CrossRef]

9. Hasbahceci M, Basak F, Acar A, Alimoglu O. A New Proposal for Learning Curve of TEP Inguinal Hernia Repair: Ability to Complete Operation Endoscopically as a First Phase of Learning Curve. Minimally Invasive Surg 2014; 2014: 528517. [CrossRef]

10. Dedemadi G, Sgourakis G, Karaliotas C, Christofides T, Kouraklis G, Karaliotas C. Comparison of laparoscopic and open tension-free repair of recurrent inguinal hernias: a prospective randomized study. Surg Endosc 2006 Jul; 20: 1099104. [CrossRef]

11. Köckerling F, Bittner R, Jacob DA, Seidelmann L, Keller T, Adolf $\mathrm{D}$, et al. TEP versus TAPP: comparison of the perioperative outcome in 17,587 patients with a primary unilateral inguinal hernia. Surg Endosc 2015; 29: 3750-60. [CrossRef]

12. Oguz H, Karagulle E, Turk E, Moray G. Comparison of peritoneal closure techniques in laparoscopic transabdominal preperitoneal inguinal hernia repair: a prospective randomized study. Hernia 2015; 19: 879-885. [CrossRef] 
13. Felix EL, Harbertson N, Vartanian S. Laparoscopic hernioplasty: significant complications. Surg Endosc 1999; 13: 328-331. [CrossRef]

14. Bringman $S$, Blomqvist $P$. Intestinal obstruction after inguinal and femoral hernia repair: a study of 33, 275 operations during 1992-2000 in Sweden. Hernia 2005; 9: 178-183 [CrossRef]

15. Dalessandri KM, Bhoyrul S, Mulvihill SJ. Laparoscopic hernia repair and bladder injury. JSLS 2001; 5: 175-177.

16. Wang WJ, Chen JZ, Fang Q, Li JF, Jin PF, Li ZT. Comparison of the effects of laparoscopic hernia repair and Lichtenstein tension-free hernia repair. J Laparoendosc Adv Surg Tech A 2013; 23: 301-305. [CrossRef]

17. EU Hernia Trialists Collaboration. Repair of groin hernia with synthetic mesh: meta-analysis of randomized controlled trials. Annals of surgery 2002; 235: 322-332. [CrossRef]
18. Grant AM, Scott NW, O'Dwyer PJ; MRC Laparoscopic Groin Hernia Trial Group. Five-year follow-up of a randomized trial to assess pain and numbness after laparoscopic or open repair of groin hernia. Br J Surg 2004; 91: 1570-1574. [CrossRef]

19. Tanrıverdi HO, Cengiz F, Yakan S, Şenlikçi A, Üstüner MA, İlhan E. Laparoskopik total ekstraperitoneal kasık fitığı tamiri konvansiyonel yönteme tercih edilebilir mi? Randomize klinik çalışma. J Clin Exp Invest 2013; 4: 80-83. [CrossRef]

20. Just E, Botet X, Martínez S, Escolà D, Moreno I, Duque E. Reduction of the complication rate in Liechtenstein hernia repair. Int J Surg 2010; 8: 462-5. [CrossRef]

21. Dulucq JL, Wintringer P, Mahajna A. Laparoscopic totally extraperitoneal inguinal hernia repair: lessons learned from 3,100 hernia repairs over 15 years. Surg Endosc 2009; 23: 482-486. [CrossRef] 